\title{
Belphégor
}

Littérature populaire et culture médiatique

$18-2 \mid 2020$

Roman Populaire Espagnol - Roman historique, 1900-1950

\section{Juan Madrid: Novelas de piratas y redescubrimiento de la aventura y la infancia}

\section{Raúl Illescas}

\section{(2) OpenEdition}

\section{Journals}

Edición electrónica

URL: http://journals.openedition.org/belphegor/3242

DOI: $10.4000 /$ belphegor.3242

ISSN: 1499-7185

Editor

LPCM

Referencia electrónica

Raúl Illescas, " Juan Madrid: Novelas de piratas y redescubrimiento de la aventura y la infancia », Belphégor [En ligne], 18-2 | 2020, mis en ligne le 11 décembre 2020, consulté le 28 avril 2021. URL http://journals.openedition.org/belphegor/3242 ; DOI : https://doi.org/10.4000/belphegor.3242

Este documento fue generado automáticamente el 28 abril 2021.

\section{(c)}

Belphégor est mis à disposition selon les termes de la Licence Creative Commons Attribution - Pas d'Utilisation Commerciale - Pas de Modification 4.0 International. 


\title{
Juan Madrid: Novelas de piratas y redescubrimiento de la aventura y la infancia
}

\author{
Raúl Illescas
}

1 La aventura constituye la esencia misma de la ficción, basta sólo pensar en Ulises o Don Quijote. Asimismo, aquella ha sido y es objeto de estudio para la filosofía, la sociología, la antropología, la pedagogía, entre otras disciplinas. Sin dudas, toda aventura conlleva la idea del viaje, que es un tema recurrente en la tradición literaria. De modo que la aventura en tanto viaje admite varias posibilidades tales como el descubrimiento, la conquista, el estudio y la crónica, pero además es una forma de evasión que supone riesgo, peligro, azar, vértigo y pruebas para convertir al aventurero en un héroe.

2 Como analiza Georg Simmel ${ }^{1}$, el viaje se configura como un sueño y la aventura es una forma de insularidad frente a la certidumbre de la rutina humana. De ahí que, la literatura que reúne todos estos relatos, por un lado, establece las condiciones de extraterritorialidad y de ucronía, que adensan y le otorgan plenitud al viaje del héroe. Por el otro, propicia también la aventura del lector. Leer es además aventurarse, una forma de asomarse al mundo y conocer al Otro.

3 La aventura es una forma de iniciación, de experimentación y de aprendizaje. En este sentido su relato se arma a partir de elementos solidarios y adversos: los primeros son aquellos que ayudan al héroe a cumplir con su itinerario, y los segundos, que pueden ser tanto físicos como morales, dificultan su recorrido. El héroe merced a las peripecias que superó, no regresa como partió y retorna con un bagaje en las distintas esferas de la vida.

4 Respecto de la aventura, Vladimir Jankélevich caracteriza la verdadera aventura como "aventura aventurosa" en la que no se busca un fin sino un estilo de vida. Recuperando a Simmel, no se refiere a aventurero sino a aventuroso que -afirma- "siempre es un principiante". Sostiene que "el territorio de la aventura es el porvenir" y agrega que "la aventura tiene desinencia de futuro (...), cuyo carácter esencial estriba en ser indeterminado"2. Por cierto y siguiendo a Jankélevich, "la aventura tienta al hombre 
porque el phatos de la aventura es un complejo de fuerzas contradictorias; la tentación es precisamente esa mezcla de ganas y horror"3.

De este modo se reconoce en la aventura la forma primigenia del relato y en el relato de aventuras una instancia fundacional en la historia literaria, que permite constituirlo como género. A partir de ello, el presente trabajo se centrará en "Los géneros y su actualización en España", en relación con las novelas de piratas. Una literatura eminentemente popular que encuentra en Juan Madrid (Málaga, 1947), un lector devoto de esas historias y un escritor, que incursiona -profusamente- en ese género. Escritor inagotable de novelas policiales, ha incursionado también, en las novelas de aventuras. Más precisamente en historias de piratas dirigidas a un público infantil y escolar. El hijo de Sandokan: una de piratas ${ }^{4}$ y Los Piratas del Ranghum ${ }^{5}$ son los objetos de este artículo. Ambos textos permiten, en primer lugar, analizar la aventura como forma de vida (Lebensform) y forma de experiencia (Form des Erlebnes) ${ }^{6}$, y el vagabundeo ${ }^{7}$. En segundo lugar, considerar a Madrid en su condición de lector y escritor de literatura de aventuras asociada al rescate de la infancia, y lo que Fernando Savater denomina "La evasión del narrador"s. Todo ello permite recuperar y transmitir la fascinación por ese género, autores, personajes y el espacio y la aventura marinos ${ }^{9}$. En tercer lugar, ambas novelas permiten considerar la importancia de la narración oral, el procedimiento cervantino del manuscrito encontrado y una lectura de las formas de colonialismo.

Por último y dadas las características de las novelas de piratas y su relación con la infancia, pueden leerse historias entre la acción y la nostalgia, que no renuncian en absoluto, a la memoria política de España.

\section{Piratas}

7 Se puede afirmar que los piratas están presentes desde tiempos inmemoriales ${ }^{10}$, cuando el mar dejó de ser solo un ámbito de navegación para convertirse en un medio para comerciar; históricamente, la piratería se constituyó en una actividad de saqueo organizado o bandolerismo marítimo que se desarrollaba en aguas o en espacios no sometidos a la jurisdicción de estado alguno. Los piratas robaban la carga, secuestraban a los pasajeros por quienes exigían rescate o bien los convertían en esclavos $\mathrm{y}$, en muchos casos, se quedaban con la nave. Se pueden hacer las diferenciaciones respecto de la condición de piratas, corsarios, bucaneros y filibusteros, sin embargo el denominador común que los agrupaba era el oro ajeno. La búsqueda de este elemento y las consecuentes acciones, los colocaban en un lugar importante y la literatura se encargó de recoger y crear un género con una masividad insospechada. Así, en las aventuras de piratas lejos de cualquier relación con la historia, los protagonistas tan brutales como caballerescos, llevaban a cabo acciones que permitían una rápida identificación de los lectores con estos Robin Hood del mar. De ahí que estos fueran invitados a ampliar horizontes y fueran impelidos a traspasar fronteras y establecer relaciones con otros mundos. Era el imperio de la geografía ya sea a través de un planisferio o un globo terráqueo $y$, en la actualidad, mediante Internet.

8 Ahora bien, la palabra pirata posee in nuce, la idea de aventura. Procede del latín pirāta,


puede traducir como intentar, pretender con empeño, experimentar, arriesgar y, por extensión, ir a la aventura. Si como afirmé, los piratas existen desde épocas antiguas, las historias de piratas están presentes en la cultura y en la historia españolas dada su 
condición imperial y la constitución de colonias en América. Se podría especular que la bandera con la calavera tiene su aparición a partir de las expediciones descubridoras de España y Portugal. Sin dudas y luego del descubrimiento de América, la bula papal del 3 de mayo de 1493 a favor de los Reyes Católicos, y el posterior Tratado de Tordesillas, el 7 de junio de 1494, son los que colocan a la corona española en el corazón de la tormenta. El papa Alejandro VI mediante la bula Breve Inter caetera II y, posteriormente, el compromiso de Tordesillas, otorgó a Fernando e Isabel el monopolio del comercio en las nuevas tierras descubiertas y por descubrir, en una línea situada 370 leguas al oeste de las islas de Cabo Verde ${ }^{11}$.

9 A la presencia de los piratas es necesario incluir la figura del mar. Este es cifra de la peripecia humana y como afirma Hans Blumenberg “(...) el naufragio es una suerte de "legítima" consecuencia de la navegación, mientras que el puerto felizmente alcanzado - la apacible bonanza son sólo un aspecto engañoso de una tan profunda problematicidad"12. Navegar es transgredir fronteras y la navegación es sinónimo de peligro, en oposición a las certezas propias de tierra firme. Al respecto Blumenberg señala que "dos presupuestos determinan la carga significativa de la metafórica de la navegación y el naufragio: por una parte, el mar como límite natural del espacio de las empresas humanas y, por otra, su demonización como ámbito de lo imprevisible, de la anarquía, de la desorientación. Incluso en la iconografía cristiana el mar es el lugar de manifestación del mal, con el rasgo gnóstico añadido de que simboliza la materia bruta que todo lo engulle y reabsorbe"13. Es entonces que el mar señala el eje del desarrollo narrativo en clave de sucesión aventurera que propone la travesía.

En la literatura española, la presencia de estos señores del mar se puede reconocer tempranamente- en La Dragoneta (1598), de Lope de Vega cuyo protagonista es el corsario Sir Francis Drake. En este poema épico y en un juicio ante Dios de las distintas naciones, se celebra la victoria de España sobre la armada inglesa y la muerte de "el Dragón" Drake en 1595, frente a las costas de San Juan de Puerto Rico. La piratería se encuentra también en la obra de Miguel de Cervantes ${ }^{14}$. La lucha es contra los piratas berberiscos o de Berbería de los hermanos Barbarroja, que en 1515 se apoderan de Argel. Los Barbarroja convirtieron esa ciudad en la república corsaria, que posibilita el nacimiento de un hombre económico moderno, en la medida que un esclavo podía llegar a ser un señor. De modo que Cervantes, cautivo en esa ciudad entre 1575 y 1580, dio cuenta de esa experiencia vital tanto en El Quijote (1605-1615) como en la novela bizantina, Los trabajos de Persiles y Sigismundo (1617). El Romanticismo no pudo estar al margen de las aventuras de este tipo de héroes anticonvencionales. José de Espronceda y La canción del pirata (1840) es la idealización de aquellos:

Que es mi barco mi tesoro, que es mi dios la libertad, mi ley, la fuerza y el viento, mi única patria, la mar. ${ }^{15}$

11 Por último y en una enumeración incompleta, Benito Pérez Galdós hace referencia a los distintos piratas, en Los episodios nacionales.

\section{La importancia de Emilio Salgari}

12 Emilio Salgari (Verona, 1863 - Turín, 1911) es un escritor sinónimo de novela de aventuras, que acompañó la infancia y la juventud de miles de lectores. Trabajó como 
periodista y bibliotecario ambulante pero, sin dudas, fue cuando se instaló en el barrio genovés de Sampiedrarena frente al mar, la situación que lo impulsó a dedicarse a esa vida aventurera de la escritura.

Como señala Fernando Savater en el "Prólogo" a Mis memorias del escritor:

Quiso ser marino, pero dejó a medias su formación náutica y en toda su vida apenas hizo en barco unas pocas excursiones y un crucero modesto por el Adriático. Sin embargo, como periodista primero y como novelista después, ya nunca dejó de navegar. En junco, en fragata, en bergantín, en galeón y en canoa, por el golfo de Bengala, el mar de la China o de las Antillas, por el río Orinoco y el padre Nilo, por el Ártico... Navegó ya toda su vida por el azul de los atlas y las ilustraciones coloreadas de las enciclopedias. Hay poetas de lo íntimo que escriben hacia adentro y poetas de lo exótico y remoto, que escriben hacia fuera y a lo lejos. A esta última tripulación perteneció Salgari y no seré yo quien le hubiera querido de otro modo ${ }^{16}$.

14 En lo que a piratas se refiere -dentro de su producción de más de ochenta novelasescribió dos ciclos relevantes para este trabajo: el de Los piratas de Malasia y el de Los corsarios del Caribe.

La serie de historias sobre piratas asiáticos comienza con Los misterios de la jungla negra (1895); aquí los protagonistas son Kamamuri, Tremal-Naik y la geografía es India. Es en Los piratas de Malasia (1896), en el que aparece por primera vez Sandokán, un noble malayo huérfano y destronado. Su compañero inseparable es el portugués Yáñez de Gomera, y la isla de Mompracem, próxima a Borneo, se constituye en su cuartel general. La sucesión de aventuras es la siguiente: Los tigres de Mompracem (1900), Los dos tigres (1904), El rey del mar (1906), A la conquista de un imperio (1907), El regreso de Sandokán (1907), La reconquista de Mompracem (1908), El brahmán del Assam (1911), La caída de un imperio (1911) y se cierra con la novela póstuma La revancha de Yánez (1913). Los cuatro amigos Sandokán, Yáñez, Kamamuri y Tremal-Naik desarrollan aventuras y acciones que dan cuenta de su actitud antiimperialista. Sus enemigos comunes son las naciones extranjeras con vocación colonialista, sobre todo Gran Bretaña, y, en menor medida, España y Holanda. Sus eventuales socios son los Thugs en el reino indio de Assam y el Sultán de Varauni en las Indias Orientales. La solidaridad de Sandokán los reúne a todos ellos combatiendo ya sea en el mar o en la jungla. Así, a lo largo de estas once novelas se comprueba cómo Sandokán, apodado El Tigre de Malasia se constituye en el mayor oponente de los británicos, quienes destruyeron su reino de Mompracem y mataron a sus padres. Esta caída del héroe en desgracia es el motor de su venganza, que lo convierte en pirata secundado por sus leales combatientes. Dicha actitud ciega de revancha y reparación encuentra su regulación en la figura de Yáñez, un personaje reflexivo y con sentido común. Como en toda historia de piratas construida sobre la acción constante, el exotismo, la valentía y la amistad, no podía estar ausente el amor. Es precisamente Yáñez quien le hace referencia a su amigo sobre Lady Mariana, la sobrina del gobernador de la colonia inglesa de Labuán. Apodada La Perla de Labuán será un nuevo motivo de aventuras del Tigre de la Malasia.

El segundo ciclo Los corsarios del Caribe (aunque ambos fueron contemporáneos en su escritura), está organizado en cinco novelas que tienen como protagonista al Corsario Negro, Emilio di Roccanegra, señor de Ventimiglia. Es un noble italiano que deviene pirata para vengar la muerte de su hermano, a manos del gobernador de Maracaibo. La zaga se constituye también a partir del pilar amoroso: el romance con la hija de su enemigo. 
17 A pesar de su condición de escritor de aventuras por excelencia, no fue ni leído ni apreciado en Inglaterra ni Francia. Sí, fue un verdadero suceso en Italia, España y la Argentina ${ }^{17}$. Más allá del éxito comercial pero por varias razones, Salgari no puede colocarse a la misma altura que Robert L. Stevenson, Joseph Conrad, Julio Verne o Rider Haggard. Quizás porque por un lado, Salgari carecía del respaldo de un imperio, ni tan siquiera de una lengua -por el contrario sus ficciones dan cuenta de una crítica al imperialismo británico- y, por el otro, su producción no contemplaba una idea de progreso científico como es el caso de Verne. Ahora bien y como todos ellos y a pesar de su marginalidad literaria, Salgari escribió para sobrevivir.

Miente sobre sí mismo, se autodenomina "Capitán" y hace de su vida una aventura para convertirse en un fabulador en sentido amplio. En las memorias hay párrafos en los que mantiene e hiperboliza la construcción de su pasado aventurero:

Estuve dos años con el capitán Pierre. No me sucedió ninguna aventura digna de mención. Viene a mi memoria una observación que hice muchas veces en la mar. Las peripecias que ocurren a una nave son siempre del carácter de su comandante. Si el capitán es un tipo amante del riesgo, es muy probable que la nave secunde esta tendencia. Si el capitán es tranquilo y prudente, también la nave se comporta sobre la misma línea. Los sucesos de la vida tienen el color del protagonismo de los mismos. Durante estos años de navegación tuve que luchar con algún ataque de fiebre tropical. Fueron terribles ataques que me condujeron a un estado lamentable. La vida de mar se me hizo casi imposible.

Sentía una gran necesidad de reposo, de intimidad, de existencia tranquila.

En pocos años de vida marinera había reunido una infinidad de impresiones: los hechos de que había sido protagonista eran suficientes para constituir un magnífico desahogo a mis ansias de aventuras. ¿Qué más podía desear? ${ }^{18}$.

19 En cualquier caso, Salgari como Scherezade, tiene la necesidad de contar para sobrevivir. Así, no sólo hace de la peripecia aventurera el motor de su escritura sino que también, genera nuevos narradores y fabuladores (Vg. Juan Madrid).

\section{Un tal Juan Madrid}

Juan Madrid es hijo de la posguerra y de la dictadura franquista. Situación a considerar en la medida que si España vivió duras condiciones de supervivencia, dado el aislamiento que le aplicó el resto de Europa, lo fue aún más, para los vencidos -los republicanos- $y$ sus familias, ya fuera al interior o en el exilio.

Como se puede comprobar, en la escritura de Madrid hay un fuerte componente autobiográfico, que podría sintetizarse en algunos lugares o espacios: Málaga y sus calles, el río Guadalmedina -evocado una y otra vez en sus novelas- y el mar Mediterráneo, que habitó en ambas orillas (parte de ella transcurrió en Marruecos). Sobre todo el -la- mar durante su infancia es artífice de un sinnúmero de relatos posibles, de aventuras por venir. Su biografía como tantas otras infancias de posguerra transcurrieron y se cobijaron en las historias y las aventuras; los medios fueron los libros, las aventis y el cine. Todo este registro de cultura popular coloca a Madrid en sintonía con Juan Marsé. Este escritor catalán establece su usina de la imaginación infantil en el cine Roxy, de Barcelona. Así, felices e interminables tardes de lecturas y de celuloide posibilitaron una alianza indestructible entre los niños y los piratas; todos ellos intrépidos, galantes y seductores, que como defensores de los humildes y de las causas perdidas, contrariamente al Quijote -y para beneplácito de lectores y 
espectadores- eran invencibles. Historias que tanto los niños en los relatos de Madrid como en los de Marsé tratarán de experimentar en sus vagabundeos barriales ${ }^{19}$.

\section{Las novelas} Juan, su alter ego. En Los piratas del Ranghum, primera entrega de la serie ${ }^{20}$, se pueden reconocer dos historias en paralelo: la aventura de Salvador y la vida de Juan, su familia y sus compañeros. acompañado por su hermano Carlos, su amigo Mohamed y Clara, la hija de una amiga de su madre. (Una "enterada" que llega para poner en crisis ese universo masculino). Emulando las historias de piratas, ellos se enfrentan -aunque comprueban que no eran tan malos- a los niños de El Perchel, barrio situado al otro lado del río Guadalmedina que atraviesa la ciudad de Málaga, "nuestros enemigos del otro lado del río"21.

La historia de Salvador se desarrolla en 1922. El viejo narrador era en aquel entonces segundo timonel del barco Ranghum, construido en Lisboa en 1876. Más tarde, en 1910, la nave fue vendida a una compañía filipina y transformada en transporte mixto de carga y pasajeros. En ese viaje -cuenta Salvador- transportaban unos pocos pasajeros y -bajo la etiqueta de "maquinaria agrícola"- armas para "los insurrectos de Timor". La tripulación constituía el barco en un espacio cosmopolita: el capitán Anastasio Zimu era filipino aunque educado en la marina imperial japonesa, el escocés Mr. Tracy era el jefe de máquinas, el gaditano Quiñones ostentaba el cargo de piloto, el segundo oficial era Mr. Riu, un filipino apodado por la tripulación "Mister Silbato" y Zing era el cocinero malayo. Dado que Sr. Zimu estaba enfermo y morirá a bordo, el Ranghum estaba bajo las órdenes del primer oficial de cubierta, el libanés Sandor. Asimismo, el cosmopolitismo al que se hizo referencia se explicita en las diferentes lenguas:

Varias veces sorprendía a Riu y a Sandor enzarzados en cuchicheos en una lengua extraña que no era tagalo, que se habla en Filipinas, ni el árabe común, lenguas en las que yo no me podía defender ${ }^{22}$.

La historia se desarrolla camino a Manila y como toda novela de piratas posee una condición, una cualidad decisiva: amplía nuestros horizontes y nos impele a traspasar fronteras y relacionarnos con otros mundos. Allí viajaban el señor Ebenezer y su hijo Aaron. Este último resulta un personaje decisivo en la trama por varias razones. En primer lugar, porque en el momento en que Sandor ordena que los pasajeros ya no pueden salir a cubierta y deben permanecer en los camarotes dado el peligro de las minas, Aaron es quien le advierte a Salvador el cambio de ruta. En segundo lugar, es a través de Aaron que se reconoce un eco u homenaje cervantino en la novela. Relata Salvador: 
Sólo me miró con sus almendrados ojos y yo me estremecí. De cerca el muchacho era extraño. Su cutis era moreno, sin mácula, puro como el mejor mármol. Parecía una de esas estatuas que se ven en los museos ${ }^{23}$. Salvador y con la recuperación y edición de su diario, otra vez por la mediación de Juan. Madrid recibe un llamado telefónico de un asilo malagueño, a través del cual le comunican la muerte de "un tal Salvador Muñoz Mercader", quien le ha dejado un paquete a su nombre que contiene un manuscrito. Desde el título, la historia que le lega Salvador establece una aventura explícitamente "sandokaniana". En Gibraltar, el joven Salvador se embarca en el buque inglés "Ciudad de Bristol". Es por mayo de 1913, ya cansado de vagabundear y escaso de dinero se ve obligado a trabajar como timonel y resulta ser uno de los pocos blancos de la tripulación. El viaje no exento de peligros, tiene como objeto transportar productos agrícolas al sultanato de Borneo y retornar con materias prima. El viaje promete aventura y no defrauda. Ya desde el inicio, Salvador afirma: "Desde los primeros días de navegación por el estrecho me di cuenta de que ese viaje se convertiría en un descenso a los infiernos" ${ }^{25}$. Y efectivamente, cumple con todas las expectativas. En primer lugar, por lo que significa la vida embarcada. Allí se pone de relevancia no solo las aptitudes y destrezas en ese ámbito, sino también la lógica colonialista basada en el tratamiento inhumano que se le daba a aquél que no fuera blanco: mala y escasa comida, hacinamiento y mayor carga de horas de trabajo.

Este maltrato permite descubrir la profundidad psicológica y la diferencia respecto de las actitudes de los otros blancos que manifiesta Salvador. A partir de ello es que emerge la figura de un marinero oriental, llamado Kemal, que se constituirá en amigo de Salvador por aquellas actitudes y por la sencilla razón de que éste compartió su limón que combatía el escorbuto:

Aquella misma noche trabé amistad con un marinero que solía pasear por cubierta durante el descanso de las guardias. Éste era indostánico de unos veintiocho a treinta años, de rostro regular, frente despejada y ojos tan brillantes que parecían despedir fuego. Adornaba su rostro una recortada barba negra. Era de estatura superior a la normal y bajos sus típicas vestimentas indostánicas: el amplio pantalón ceñido a la cintura con una faja, la camisa sin cuello y el chaleco, se adivinaban una fuerza hercúlea y la agilidad de un tigre.

Aunque era un simple marinero de segunda clase, dedicado a las más duras tareas, desde el primer momento noté que su figura delataba un aplomo y una seguridad en sí mismo que a nadie que se hubiese fijado, pasaría desapercibido. También noté que el resto de sus compañeros lo trataban con enorme deferencia y respeto ${ }^{26}$.

Así Kemal, a partir de su encarcelamiento y posterior motín, aparece en su verdadera dimensión: 
Después sonó la campana del buque y entre sesenta y setenta hombres fuertemente armados, formaron en dos secciones a lo largo de la cubierta.

Entonces vi aparecer a Kemal, que bajó las escaleras del puente de mando, rodeado de dos hombres, al parecer sus oficiales. (...)

Al ver a Kemal, los hombres de cubierta irrumpieron en vítores y hurras repitiendo: “Kemakán...Kemalkán... Kemalkán!"

Este alzó la mano y mandó callar. Dio una orden a Batal, que la repitió en malayo a los que tenía más cerca. Inmediatamente dos hombres izaron una bandera en el palo de mesana: un trapo rojo con la cabeza de un tigre y dos sables cruzados. Cuando ondeó en la punta del mástil, los hombres irrumpieron otra vez en hurras y gritos. Creí entender: "Momprecem...Momprecem! ${ }^{27}$.

La toma del buque era una operación planificada desde hacía un año por el Ejercito de Liberación de los Sultanatos Independientes, que lideraba Kemalkán. El barco no transportaba artículos agrícolas sino armamento para los esbirros del colonialismo británico. De modo que a partir de allí tanto Salvador como los lectores comprendemos la verdadera trama de la historia que era la lucha de los nacionalistas índicos. El viaje a bordo de "Ciudad de Bristol" nos depara una angustiante persecución naval por parte de la flota de la corona británica y una aventura en la selva de la Isla de Borneo, donde Salvador cae en manos de caníbales. Asimismo, en estas peripecias que supera el protagonista, el amor o lo que él cree que es eso, ocupa un lugar decisivo. En cuanto el buque se hace a la mar en Gibraltar, el protagonista descubre a Lady Janette Bloson, una joven inglesa desenfadada y egoísta, hija de armadores navieros, que viaja para casarse con el Sultán de Brunei, Mohamed Arei Balza Ben Krisnamurti, a quien había conocido en la Universidad de Oxford.

La seducción es inmediata y todos los pasos que da a partir de la relación con Lady Janette determinan la tensión entre dos "fidelidades": por un lado, a la amistad con Kemal y, por el otro, a su pasión por la caprichosa Janette. Las acontecimientos se suceden y el relato no decae porque siempre nos depara una sorpresa. El manuscrito acaba con la separación de Lady Janette y Salvador, que la deja al cuidado de los británicos. El Diario de mi viaje a Borneo -en origen- había sido confeccionado por la joven y entregado a Salvador cuando se despidieron. Y la edición del mismo finaliza con un escrito de Juan Madrid: "A manera de epílogo", en el que cuenta su rastreo de la dama y de Kemalkán. Madrid realiza una investigación concienzuda basada en bibliografía y comunicaciones con instituciones. Finalmente, nos reserva un fragmento del "supuesto diario de Lady Janette" en el que confiesa estar embarazada de un joven marinero español.

Los piratas del Ranghum representa la escena de la oralidad, la presencia imprescindible de Salvador para los niños y la infancia malagueña de los personajes, inmersos en la posguerra y la dictadura. En esta novela se asiste al proceso de formación de Juan Madrid como escritor a partir de los relatos del marino. En ese contexto, la escritura de Juan no renuncia a las condiciones socio-políticas imperantes de su familia, como una de las tantas familias republicanas. Por ello, tanto en esta novela como En el Mar de China y El fugitivo de Borneo, se puede apreciar la vida durante el Franquismo.

En cuanto a la categorización de novela juvenil al texto y la serie en general, un dato contundente es que -desde el inicio- precisa la situación familiar a partir del encarcelamiento de su padre. Es decir, mientras que la historia de Salvador funciona como una forma de evasión, la situación del padre es un anclaje a su realidad y determinante para Juan en lo individual. En primer lugar, de su escritura: "Era un 
cuaderno que había pertenecido a mi padre antes de que lo encarcelaran" ${ }^{28}$. En segundo lugar, era el pretexto y la mentira para no concurrir a la escuela:

Como mi padre estaba en la cárcel -igual que mucha gente tras la guerra-, inventamos un truco: le dijimos a mi madre que los maestros nos hacían cantar el Cara al Sol por las mañanas, antes de entrar a clase. Mi madre nos sacó del colegio inmediatamente y decidió darnos clases en casa ${ }^{29}$.

En tercer lugar, la vinculación con su padre se mantenía de forma epistolar: "Mi madre nos dijo que nuestras cartas le ayudaban mucho a nuestro padre en la situación en la que estaba" ${ }^{30}$. En cuarto lugar, las "visitas" de la policía franquista que por su aspecto, el narrador asimilaba a los malos de las historias de Salvador. Por último y como modo de ratificar el verosímil y descartar lo "políticamente correcto" propio de la literatura infanto-juvenil, Juan el narrador y protagonista, que está inmerso en un contexto y en un mundo de aventuras marcadamente masculino, puede explicitar su pensamiento en ocasión de la presencia incómoda de Clara y el peligro inminente de la banda del Perchel: "Y yo pensé: "Qué bueno que te cojan, Clara, ojalá te torturen y no vuelvas más" ${ }^{31}$. Esa idea fusiona una escena clásica del mundo de piratas y la situación de su padre preso.

En cualquier caso, se puede corroborar cómo la historia oral de Salvador desborda sus propios márgenes para otorgarle significación y sentido a la cotidianeidad del narrador y sus amigos. Por añadidura, la oralidad es otra forma de construcción de la aventura. A propósito, hay una serie de situaciones que permiten corroborar lo afirmado. Evidentemente, Mohamed, amigo del protagonista, es un personaje proteico que está construido en la mentira. Por un lado, Mohamed miente a sus amigos sobre los golpes que le inflige su padre. Por otro, cómo le miente a su padre, cuando va a la casa Juan a aprender a leer, escribir y dibujar en lugar de trabajar. Además, su padre, el señor Abdul, es un personaje de matriz picaresca cuya actividad es la de vendedor ambulante de aceite de lagarto. El modo en que presentaba su producto y explicaba las bondades del óleo constituía una verdadera puesta en escena comparable al tratado del Buldero, de El Lazarillo de Tormes. Acompañado por Rasputín, el lagarto que "había sido del abuelo de su padre", una batería de frasquitos con el aceite que curaba una amplio espectro de males y su amante llevaba a cabo estafas cotidianas.

Sin dudas, Los piratas del Ranghum es una novela sobre piratas en la cual Salgari y sus personajes proveen a Salvador de todos los elementos propios del género, y son material de referencia para Juan y sus amigos para pensar las estrategias de supervivencia en su barrio y aledaños. La aventura barrial tiene una estrecha relación con el vagabundeo y el río Guadalmedina se constituye como una frontera puesto que del otro lado vivían los chicos del Perchel. Además, el río era un espacio rico y riesgoso: guardaba tesoros modestos pero invalorables para ellos, dada la posibilidad de venta, y ponía en evidencia el problema de los límites y la conquista del territorio. El peligro y las peripecias de los jóvenes héroes a partir de la ocupación y cruce de fronteras se verifica en la excursión como forma de conseguir un tesoro. Lo descubierto se reinvertía en formas momentáneas de felicidad y de inmersión en otras aventuras. En otro orden, lo descubierto en el río se constituía como propiedad. A propósito de los del Perchel, el narrador afirma:

-No nos dejan recoger tesoros- añadí yo.

-Eso es injusto- repuso ella. Los tesoros son para los que los encuentran, ¿no ${ }^{32}$. 

descubrimiento de tesoros, la piratería y el problema de la propiedad:

Como era verano, el río Guadalmedina estaba medio seco en nuestra orilla. (...) Era muy peligroso pasear por allí, porque nuestros enemigos, los chicos del barrio del Perchel, conocían los vados y atravesaban el río para atacarnos. Ellos decían que el río era suyo y que nadie podía robar los tesoros que encerraba el barro. Y había montones de tesoros; tesoros que se podían vender a los traperos y conseguir así dinero para alquilar tebeos, comprar caramelos, altramuces, palotes de palodú, o sea regaliz, y hasta chicle americano Bazoca, "siempre en la boca" como decía Paquito el Cojo, el hombre que los vendía en el quiosquillo de la calle Carreterías, un poco más arriba de donde vivíamos.

El tesoro que más valía era el cobre; después, el hierro, el plomo, el alambre, las latas y los cascos de botellas. El cartón, los papeles y los cascos de botellas eran lo que menos valía ${ }^{33}$.

El personaje de Salvador es una construcción riquísima. Su condición fundamental es el halo misterioso a partir de la soledad en la que vive y la escasa información de que se dispone. Habita en la playa junto a Rayo, el perro mudo, “(...) que no podía ladrar porque una vez alguien la había intentado cortar el cuello con un cuchillo y le había cercenado las cuerdas vocales" ${ }^{34}$.

Salvador, que tenía una pierna de palo, vivía de lo que obtenía en el mar, de donde también provenían sus narraciones. La casucha de lata en la que habitaba se convirtió para los niños, en la Meca de los relatos de piratas.

41 Su condición de personaje para los niños radicaba -como se dijo- en el misterio o en algunas vagas referencias sobre su persona. Por ejemplo, a propósito de la historia del Ranghum, afirma: "Fijaos, yo nunca he sabido la edad exacta que tengo. Sé que ahora soy muy viejo y que entonces era muy joven y muy fuerte" ${ }^{35}$.

Luego, se pueden observar las especulaciones que sobre Salvador y sus historias hacen los niños:

Esta noche he pensado mucho en la historia de Salvador -dijo mi hermano-. Fijaos, abrió la puerta de los camarotes y se encontró con Sandor apuntándole con una pistola. ¿Qué creéis que pasó?

-Hasta que no nos lo cuente no lo sabremos -dijo Clara.

-Yo creo que le disparó. A lo mejor le hirió -añadió mi hermano.

-Puede que lo hiriera en una pierna. Por eso Salvador lleva pata de palo.

-Salvador no quiere contar cómo perdió la pierna -dije yo con desprecio-. Nunca lo va a contar. Tuvo que pasar otra cosa la noche aquella en que Sandor lo apuntó con una pistola.

No le dije a esa chica tan tonta que yo lo sabía.

La noche anterior había escrito en mi cuaderno lo que le pasó a Salvador cuando Sandor le apuntó con una pistola ${ }^{36}$.

Tal vez en las novelas analizadas, el acercamiento más preciso a la literatura de Juan Madrid sea a través de los paratextos. Por un lado, la dedicatoria, el prólogo y el epílogo que hace en El hijo de Sandokán y, por el otro, "Como un prólogo" correspondiente a Los Piratas del Ranghum.

En la dedicatoria, Madrid escribe: "A Emilio Salgari, que me hizo contador de historias". Aunque breve, esta permite relevar en primer lugar, la decisión de dedicar el libro a Emilio Salgari, con quien establece cierta familiaridad, cierta filiación, a partir de la lectura. En segundo lugar, la lectura de esta literatura y su relación con la infancia. Es decir, la posibilidad de "hacerse a la mar", en esas embarcaciones de papel que son los 
libros. Y, en tercer lugar, la contingencia de heredar un oficio; me refiero a la condición de "contador de historias" de Juan Madrid, o sea, el haberse convertido en escritor. Aunque para Madrid ser contador supone algo más que escritor, remite a la escena primigenia de la literatura, que es pura oralidad frente a un auditorio absorto y expectante de historias que llevan al límite la imaginación. Como analiza Maite Alvarado: "Cuando aún no existían los derechos de autor y los escritores dependían, en buena medida, de la generosidad de protectores y mecenas para poder publicar sus obras, las dedicatorias cumplían una función de reconocimiento o compromiso" ${ }^{37}$. En tal caso, esta dedicatoria funciona como el reconocimiento de un don; y, lejos de ser una "retórica hueca", manifiesta una potencia infinita.

"Como si fuera un prólogo" cuenta las últimas noticias de Salvador y el paquete que lega a Juan Madrid. El fardo contenía un revólver Nagant, una brújula inglesa, un parang o machete malayo y un diario personal de 1913. El narrador sortea los obsequios con su hermano Carlos y resulta poseedor del arma de fuego y del Diario de mi viaje a Borneo. Asimismo, recibe una carta para Juan Madrid, pero que en realidad es para su padre, quien lleva el mismo nombre. Ello le permite descubrir que ambos habían luchado en el bando republicano. Los manuscritos del diario resultan una aventura en sí mismos, dado que: "El papel se rompía y el tiempo había desdibujado de tal manera las letras que era casi imposible descifrarlas"38. Por este motivo y como en la constitución del manuscrito del Quijote, Madrid agradece a quienes ayudaron a descifrar aquellas páginas. También denuncia su intervención en el texto como editor: "Por todo ello me atrevo a decir que estamos ante la descripción de hechos reales y no de una verdadera novela, a pesar del carácter de aventura -a veces increíble- que tiene esta narración" ${ }^{39}$. Finalmente, "A manera de epílogo" funciona como modo de documentar la historia. Como en ambas novelas, Madrid se sirve de enciclopedias, diarios y referencias a tratados internacionales.

Por su parte, "Como un prólogo" de Los piratas del Ranghum establece la continuidad entre realidad y ficción, entre los sueños y las historias que narraba Salvador y lo que el protagonista plasmaba en el cuaderno de tapas negras, vínculo entre el pasado y el presente. A partir de ello, desde el presente, va a continuar y finalizar la historia de los piratas del Ranghum. Es, además, la continuidad de padres a hijos, de contadores a oyentes, de las historias hiladas por Salvador. Es el pasaje del universo de la oralidad al de la escritura. Y, finalmente, es la certeza de la realización del proyecto personal de Madrid.

\section{Conclusión}

Jean-Yves Tadié en su ensayo La novela de aventuras, afirma: "Una novela de aventuras no es solamente una novela de aventuras; es un relato cuyo fin primordial es contar aventuras, y que no puede existir sin ellas" ${ }^{40}$. Esta situación es la que establece un vínculo sumamente especial entre Salvador y Juan y que remite no a experimentar la aventura -accidentes, trampas, enemigos, elementos inmateriales- sino a la experiencia de contarla, de mantener un auditorio en vilo o el libro abierto. Es también como el viaje solitario del héroe, en el que el estilo y el suspense determinarán la adhesión de los oyentes o lectores angustiados y expectantes. Todo ello evoca la idea que expresa Fernando Savater cuando se refiere a "la evasión del narrador": 
El narrador de historias siempre acaba de llegar de un largo viaje, en el que ha conocido las maravillas y el terror. (...) Así, tras el rostro del hombre que llega de muy lejos, espera el fluir de las historias. Pero el viaje no siempre ha consentido al viajero protagonizar la aventura, muchas veces ha debido contentarse con escuchar la peripecia de labios de otros, sentados ante un jarro de cerveza en la taberna llena de gente y de humo o atento al cuchicheo crispado de labios del moribundo, cuyos ojos comienzan a familiarizarse con los fantasmas. Quizás ha leído la historia asombrosa en el manuscrito hallado en una botella o en un grimorio maldito que el librero, con buen acuerdo se negaba a vender ${ }^{41}$.

Esta referencia alcanza a Salvador y, sobre todo, a Juan e incluso a su hermano y amigos. (Tanto Salvador como Juan prescinden del humor, es decir que el procedimiento se traduce en un relato in crescendo). En el caso de Juan, los relatos del marino le producen la necesidad y la obligación de mantener vivas esas historias.

Por su parte, Salvador -en ese contexto de encierro y prohibiciones que fue el Franquismo- es el homo viator como sinónimo de libertad. Sus viajes y aventuras son leídas por los niños en clave de nomadismo, una forma arcaica de supervivencia que privilegia la libertad. Precisamente, Maffesoli -a propósito del nomadismo- lo relaciona con la existencia humana:

No olvidemos que el término mismo de existencia (ex-istencia) evoca movimiento, ruptura, la partida, lo lejano. Existir es salir de sí mismo, es abrirse al otro, aun transgrediendo. Por cierto, la actitud de transgredir es invariablemente la señal más clara de una energía activa, de una fuerza vital que se opone al poder mortífero de las diversas formas de encierro ${ }^{42}$.

Para finalizar y teniendo en cuenta que estas novelas intentaron pensar "Los géneros y su actualización en España”, se puede afirmar que Juan Madrid en la constitución de las dos historias -la de Salvador y la de Juan- opera desde la concepción simmeliana de la aventura como forma de vida y como forma de experiencia. Ambas cristalizadas en el personaje de Salvador y, de modo reflejo, en Juan. Las historias y aventuras que desgrana el viejo se sustentan en una extraterritorialidad que, aunque verificable en los mapas: Gibraltar, el mar Mediterráneo, Malta, Chipre, el canal de Suez, el Mar Rojo, el estrecho de Bab-el-Mandeb, Borneo, Brunei, etc., resultan un eficaz antídoto contra la realidad imperante en España. Juan, su hermano Carlos y sus amigos logran evadirse como oyentes y como modestos aventureros barriales. Juan se evade escribiendo las historias de Salvador y Carlos, Clara y Mohamed imaginándolas.

\section{NOTAS}

1. Georg Simmel: "La Aventura", en: Sobre la aventura. Ensayos de estética, Barcelona: Península, 2002. Pp. 17-35. (Trad. Gustav Muñoz y Salvador Mas).

2. Vladimir Jankélévitch: "La aventura" en La aventura, el aburrimiento, lo serio, Madrid: Taurus, 1989, pp. 12-40. (Trad. Elena Benarroch).

3. Ibid., p. 14.

4. Juan Madrid: El hijo de Sandokán: una de piratas, Madrid: La esfera de los libros, 2003.

5. Juan Madrid: Los piratas del Ranghum, Barcelona: EDEBE, 2009. 
6. Cf. Simmel, 2002, ibid. y Jankélévitch, 1989, ibid.

7. Michel Maffesoli: "Sociología de la aventura", en: El nomadismo. Vagabundeos iniciáticos, México: Fondo de Cultura Económica, 2005. Pp. 112-157. (Trad. Daniel González Martínez).

8. Fernando Savater: "La evasión del narrador", en: Savater, Fernando, La infancia recuperada, Madrid: Santillana/Taurus, 1994. Pp. 23-50.

9. Hans Blumenberg: "La navegación como violación de fronteras" y "Lo que queda al náufrago", en: Naufragio con espectador. Paradigma de una metáfora de la existencia, Madrid: Visor, 1995. Pp. 13-16 y 17-36. (Trad. Jorge Vigil).

10. Polibio, Historias, II, 4-12 ya lo documenta durante la Primera Guerra Púnica, (241 a.C.) y señala a Agrón, rey de los ardiaei, quien desde el este de Italia se convitió en una amenaza en el mar Adriático para los romanos.

11. No podemos obviar que el $70 \%$ de la superficie del planeta la ocupa el agua. De allí que haya habido una preocupación en términos de soberanía y jurisdicción por las posibilidades de navegación y recursos. En este sentido, el Imperio romano sustentaba la idea de un mar cerrado (Mare Clausum) y -sin explicitarlo de este modo- el derecho de la plataforma marítima de cada estado. No obstante ello, en el Derecho romano se observa una amplia posibilidad de interpretación. Por un lado, legislaba res Conmunis omnium. Desde esta perspectiva, los recursos del mar son de todos. Por el otro y donde se traducía la condición de imperio en este espacio, planteaba el res nullius por el cual, el mar no pertenecía a nadie y, por tanto, era factible de hacerlo propio a través de la conquista y la ocupación. Durante el siglo XVI, se legisla a favor de la potencias descubridoras España y Portugal en desmedro de Francia e Inglaterra, principalmente, y de Holanda. De hecho y en la práctica, estas naciones actuaron bajo la tesis de un "mar libre". Y en respuesta a la legislación papal, el jurista Hugo Grocio escribe por encargo de la compañía holandesa de las Indias Orientales, su tratado De Indis (1609), cuyo capitulo XII titulado Mare liberum afirmaba la libertad en los mares. Las controversias en cuanto a derecho internacional marítimo continuaron pero, mientras tanto, los piratas hicieron tabula rasa respecto de la situación y se dedicaron a realizar su trabajo. Cf. Antonio Gutiérrez Escudero, América: Descubrimiento de un mundo nuevo, Madrid: Ed. Istmo, 1990.

12. Blumenberg, ibid., p. 17.

13. Blumenberg, ibid., p. 15.

14. Emilio Sola y José F. de la Peña: Cervantes y La Berbería. Cervantes, mundo turco-berberisco y servicios secretos en la época de Felipe II, México: FCE, 1996. Ramiro Feijoo: Corsarios Berberiscos, Barcelona: Carroggio/Belacqua, 2003.

15. José de Espronceda: Obras poética completas, Buenos Aires: Sopena, 1938, p.146.

16. Fernando Savater: "Prólogo", en: Emilio Salgari, Mis Memorias, Sevilla: Editorial Renacimiento, 2012. (Trad. Vicente Corbi), pp. 9-10.

17. En España, a través de la Editorial Calleja, con ilustraciones de Rafael de Penagos. Tanto el editor Saturnino Calleja como el dibujante y pintor Penagos son agentes de la Modernidad en la península. El primero a través de la publicación de un amplio catálogo de diferentes disciplinas, y el último mediante la incorporación del art déco en las ediciones populares. En la Argentina, Salgari será publicado en la colección Robin Hood, ilustrado por Pablo Alejandro Pereyra. Asimismo, los hermanos italianos Cesare y Vittorio Civita (con la ayuda de Boris Spivakov), crearon la Editorial Abril, que funcionó entre 1947 y 1961. Dieron gran impulso a los cómic para adultos. "Salgari" fue su primera revista. Sandokán como personaje exótico fue también un héroe radial. Como investigó Ernesto Goldar (1992), a las seis de la tarde por Radio Splendid, Sandokán, El Tigre de la Malasia, permitía viajar a los arrabales del mundo -solo a través de la voz y otros 
sonidos ambiente- a la infancia durante los años cincuenta. (Véase: Ernesto Goldar: Buenos Aires: vida cotidiana en la década del 50, Editorial Plus Ultra, 1992. Capítulo VII: La cultura).

18. Emilio Salgari, ibid., pp. 91-92).

19. Las décadas de los cuarenta y los cincuenta fueron épocas doradas para el cine de piratas y las novelas de Salgari, materia prima imprescindible para el Séptimo arte. Quizás, el pirata de la pantalla por antonomasia haya sido Errol Flynn en el El Capitán Blood (1935), de Michael Curtiz. El protagonista es un doctor irlandés que participó en la Rebelión de Pitchfork (1685) contra Jacobo II, último rey católico de Inglaterra. Condenado como esclavo en Barbados se escapa y se convierte en pirata.

20. La novela forma parte de la colección "Recuerdos de piratas" publicada por la editorial EDEBÉ y es una lectura recomendada a partir de los diez años. Los libros que la componen son En el Mar de China (1997), El fugitivo de Borneo (1998) y El Rey del mar (2010). De este modo, puede catalogarse como literatura infantil o juvenil; sin embargo, Madrid propone lecturas que exceden esta categoría. Resulta interesante el modo de presentar la edición. Hay dos tipos de letras y por tanto dos modos de diseñar las páginas. Las letras más pequeñas determinan la situación del narrador, su familia y el contexto socio-político, y la historia del Ranghum, que Juan escucha, escribe y fija. La historia que narra Salvador tiene una letra más grande, modo de proporcionales mayor importancia al relato oral "original".

21. Juan Madrid, 2009, ibid., p. 9.

22. Juan Madrid, 2009, ibid., pp. 28-29.

23. Juan Madrid, 2009, ibid., p. 26.

24. Juan Madrid, 2009, ibid., p. 27.

25. Juan Madrid, 2003, ibid., p. 17.

26. Juan Madrid, 2003, ibid., pp. 19-20.

27. Juan Madrid, 2003, ibid., pp. 47-48.

28. Juan Madrid, 2009, ibid., p. 7.

29. Juan Madrid, 2009, ibid., pp. 7-8.

30. Juan Madrid, 2009, ibid., p. 36.

31. Juan Madrid, 2009, ibid., p. 16.

32. Juan Madrid, 2009, ibid., p.16.

33. Juan Madrid, 2009, ibid., p. 14.

34. Juan Madrid, 2009, ibid., p. 18.

35. Juan Madrid, 2009, ibid., p. 51.

36. Juan Madrid, 2009, ibid., pp. 42-43.

37. Maite Alvarado: Paratexto, Buenos Aires: Eudeba, 2010., p. 21.

38. Juan Madrid, 2003, ibid., p.11.

39. Juan Madrid, 2003, ibid., pp. 12.

40. Jean-Yves Tadié: La novela de aventuras, México: Fondo de Cultura Económica, 1989. (Trad. José Andrés Pérez Carballo)., p. 7.

41. Fernando Savater, 1994, ibid., p. 25.

42. Michel Maffesoli: "El impulso de la vida errante", en: El nomadismo. Vagabundeos iniciáticos, México: Fondo de Cultura Económica, 2005. Pp. 19-34. (Trad. Daniel González Martínez), pp. 31-32. 


\section{RESÚMENES}

Juan Madrid (Málaga, 1947) es sinónimo de literatura popular. Escritor inagotable de novelas policiales, ha incursionado también, en las novelas de aventuras. Más precisamente en historias de piratas dirigidas a un público infantil y escolar. El hijo de Sandokan: una de piratas (2003) y Los Piratas del Ranghum (2009) son los objetos de este artículo. Ambos textos permiten, en primer lugar, analizar la aventura como forma de vida (Lebensform) y forma de experiencia (Form des Erlebnes) y el vagabundeo. En segundo lugar, considerar a Madrid en su condición de lector y escritor de literatura de aventuras asociada al rescate de la infancia, y lo que Fernando Savater denomina "La evasión del narrador". Todo ello permite recuperar y transmitir la fascinación por ese género, autores, personajes y el espacio y la aventura marinos. En tercer lugar, ambas novelas permiten considerar la importancia de la narración oral, el procedimiento cervantino del manuscrito encontrado y una lectura de las formas de colonialismo.

\section{ÍNDICE}

Palabras claves: novela de aventuras, piratas, Emilio Salgari, Franquismo, colonialismo

\section{AUTOR}

\section{RAÚL ILLESCAS}

Universidad de Buenos Aires - Universidad Nacional de San Martín

illescas.r@gmail.com 